\title{
Neisseria gonorrhoeae Porin Modifies the Oxidative Burst of Human Professional Phagocytes
}

\author{
DIRK R. LORENZEN, ${ }^{1}$ DIRK GÜNTHER, ${ }^{2}$ JASMINE PANDIT, ${ }^{2}$ THOMAS RUDEL, ${ }^{1}$ \\ ERNST BRANDT, ${ }^{3}$ AND THOMAS F. MEYER ${ }^{1,2 *}$ \\ Abteilung Molekulare Biologie, Max-Planck-Institut für Infektionsbiologie, D-10117 Berlin, ${ }^{1}$ Abteilung Infektionsbiologie, \\ Max-Planck-Institut für Biologie, D-72076 Tübingen, ${ }^{2}$ and Abteilung Immunologie und Zellbiologie, \\ Forschungszentrum Borstel, D-23845 Borstel, ${ }^{3}$ Germany
}

Received 20 March 2000/Returned for modification 15 May 2000/Accepted 11 August 2000

\begin{abstract}
A hallmark of infection with the gram-negative bacterium Neisseria gonorrhoeae is the local infiltration and subsequent activation of polymorphonuclear neutrophils. Several gonococcal outer membrane proteins are involved in the interaction with and the activation of these phagocytes, including gonococcal porin, the most abundant protein in the outer membrane. Previous work suggests that this porin plays a role in various cellular processes, including inhibiting neutrophils activation and phagosome maturation in professional phagocytes. Here we investigated the ability of porin to modify the oxidative metabolism of human peripheral blood neutrophils and monocytes in response to particulate stimuli (including live gonococci) and soluble agents. The activation of the oxidative metabolism was determined by chemiluminescence amplified with either luminol or lucigenin. We found that treatment of the phagocytes with porin inhibits the release of reactive oxygen species measured as luminol-enhanced chemiluminescence in response to zymosan, latex particles, and gonococci. The engulfment of these particles was not, however, affected by porin treatment. Similar effects of porin on the chemiluminescence response were observed in cytochalasin B-treated neutrophils exposed to the soluble chemotactic peptide $N$-formylmethionyl-leucyl-phenylalanine. This indicates that porin selectively inhibits granule fusion with those cellular membranes that are in direct contact with porin, namely, the phagosomal and plasma membranes. This porin-induced downregulation of oxidative metabolism may be a potent mechanism by which gonococci modulate oxygen-dependent reactions by activated phagocytes at inflammation sites.
\end{abstract}

Professional phagocytes such as polymorphonuclear neutrophils (PMN) and peripheral blood monocytes play a crucial role in the host defense against infection with microorganisms. The interaction of phagocytes with the bacteria results in the production of reactive oxygen species (ROS) due to a sequence of events collectively known as the oxidative burst. The initial event in the oxidative burst is the assembly of membranebound and cytoplasmic components into a functional enzyme complex, NADPH oxidase, which catalyzes the reduction of oxygen to superoxide anion $\left(\mathrm{O}_{2}{ }^{-}\right)$. Dismutation of $\mathrm{O}_{2}{ }^{-}$, which occurs either spontaneously or enzymatically by superoxide dismutase, results in the formation of hydrogen peroxide $\left(\mathrm{H}_{2} \mathrm{O}_{2}\right)$, which in turn serves as a substrate for myeloperoxidase (MPO). MPO is discharged from cytoplasmic granules into the phagosome during the degranulation process and converts $\mathrm{H}_{2} \mathrm{O}_{2}$ into hypochlorous acid $(\mathrm{HOCl})$, a strong oxidant that acts as a bactericidal agent in phagocytic cells $(36,45)$. Recently, it was described that MPO and MPO-derived inflammatory oxidant also participate in the generation of highly toxic nitric oxides in human PMN (18). Thus, the combination of both, NADPH oxidase activation and degranulation of MPO are necessary for efficient killing of microorganisms (26, 40). In addition to these intracellular events, an extracellular equivalent contributes to the development of an inflammatory response. Here, ROS generated by NADPH oxidase combines with released lysosomal enzymes to damage tissues in the vicinity (59).

Oxidative metabolism is absent in resting phagocytes, and

\footnotetext{
* Corresponding author. Mailing address: Abteilung Molekulare Biologie, Max-Planck-Institut für Infektionsbiologie, Schumannstr. 21/ 22, D-10117 Berlin, Germany. Phone: 49-30-28-46-04-02. Fax: 49-3028-46-04-01. E-mail: meyer@mpiib-berlin.mpg.de.
}

the phagocytes must be stimulated for ROS to be produced. Phagocytosis is one such stimulus, but ROS production can also be induced by the simple adherence of bacteria to phagocytes. Biological agents such as $N$-formylmethionyl-leucyl-phenylalanine (FMLP) or phorbol 12-myristate 13-acetate (PMA) can also stimulate the oxidative burst (7).

The facultative intracellular human pathogen Neisseria gonorrhoeae is the etiological agent of the sexually transmitted disease gonorrhea (54). During the course of infection, gonococci penetrate the epithelium of human mucosal tissues and incite a massive inflammatory response in subepithelial tissues (42). Members of the phase-variable opacity (Opa) outer membrane proteins of the bacteria participate in the invasion of epithelial cells and also act in the uptake by phagocytic cells $(6,12,24,38)$. Perhaps also playing a significant role in epithelial invasion is the porin. Porins are the most abundant proteins in the outer membrane of gram-negative bacteria, and their function is to form hydrophilic ion and nutrient channels in the virtually impermeable outer membrane $(35,49)$. Gonococcal porin has been shown to translocate from the bacterial outer membrane into epithelial cell membranes at the site of contact between the bacteria and the cell membrane, which suggests that porin may play an active role in infection (10, 35, $58,61)$. Porin, after its insertion into neutrophils membranes, may also impair neutrophil function by inhibiting phagocytosis, actin polymerization, the secretion of microbicidial enzymes, and opsonin receptor expression of stimulated neutrophils (8, 27-29). More recently, we have shown that gonococcal porin can also inhibit phagosome maturation in human macrophages (46). Furthermore, translocation of porin to target cells leads to a $\mathrm{Ca}^{2+}$ influx (47) which promotes gonococcal invasion (5) and the induction of apoptosis (47).

A variety of processes involving reactive oxygen species re- 
sults in the emission of photons and can be easily measured by chemiluminescence (CL). This CL reaction can be amplified by addition of the indicators luminol or lucigenin $(4,14)$. These indicators measure different stages of the reaction since lucigenin reacts directly with $\mathrm{O}_{2}{ }^{-}$, whereas luminol-enhanced light emission is due to oxidation of luminol by oxygen derivatives resulting primarily from MPO-catalyzed reactions $(16,19,23$, 43).

In this study we investigated the effect of gonococcal porin on phagocytosis and oxidative metabolism of human peripheral blood phagocytes. For that purpose we employed the measurement of CL, which allows continuous monitoring of the oxidative burst and is helpful to determine oxidative metabolism with respect to the time course and the magnitude of the response.

\section{MATERIALS AND METHODS}

Porin preparation. A liquid overnight culture of $N$. gonorrhoeae strain VP1 (strain collection number N131, serotype P.IA, Opa ${ }^{+}$, as described by Makino et al. [41]) was used as the source of porin. Porin purification was performed exactly as previously described (47). The protein profile of the purified porin was visualized on a Coomassie blue-stained polyacrylamide gel and is identical to that shown elsewhere (47). The porin in the resulting preparation occurred mainly in its native trimeric form, although a small amount of the monomeric form (34 $\mathrm{kDa}$ ) was also present. Porin concentrations were calculated by the Lowry method using a bovine serum albumin (BSA) solution as the standard. The stock solution was adjusted to $500 \mu \mathrm{g} / \mathrm{ml}$ in dialysis buffer $(20 \mathrm{mM}$ Tris- $\mathrm{HCl}, 150 \mathrm{mM}$ $\mathrm{NaCl}, 2 \mathrm{mM} \mathrm{MgCl}$; pH 7.8) containing $0.025 \%$ lauryldimethylalamine oxide (LDAO) and was appropriately diluted prior to use.

To reduce endotoxin (lipopolysaccharide [LPS]) contamination, the porin preparation was applied to a ResourceQ anion exchanger (Pharmacia) and washed extensively with 20 volumes of dialysis buffer. The endotoxin content was then assessed by gel electrophoresis and visualized by a specific LPS silverstaining technique as described elsewhere $(39,55)$. Despite the purifying step, detectable amounts of endotoxin were found within all porin fractions. Using the Limulus amebocyte lysate assay, we quantified the LPS contamination and received values varying between 20 and $300 \mathrm{ng} / \mu \mathrm{g}$ of protein. Consequently, we included in all experiments controls containing LPS from the gonococcal strain used as the source of porin. Gonococcal LPS was extracted from the bacterial pellet according to the method described by Galanos et al. (21) and was stored at $-20^{\circ} \mathrm{C}$.

Isolation of phagocytes. Peripheral blood mononuclear cells (PBMC) were isolated from citrated fresh human blood by density gradient centrifugation $\left(400 \times \mathrm{g}, 35 \mathrm{~min}, 22^{\circ} \mathrm{C}\right)$ over Ficoll-Isopaque $(1,077 \mathrm{~g} / \mathrm{ml}$; Biochrom $)$, washed twice with $\mathrm{Ca}^{2+}$-free phosphate-buffered saline (PBS) and resuspended in PBSA (PBS plus $0.05 \%$ BSA containing very low endotoxin concentrations [Serva]) supplemented with $5 \mathrm{mM}$ glucose. Monocytes constituted 20 to $30 \%$ of the PBMC populations used, as determined by the size measured in a F800 Sysmex Cell Counter (Digitana). Human PMN were isolated from the upper layer of the erythrocyte pellet as described previously (30). Briefly, the PMN fraction was mixed with polyvinyl alcohol (1\% [wt/vol] PVA72000 p.a. [Merck]) dissolved in $0.9 \% \mathrm{NaCl}$, and erythrocytes were allowed to sediment for $30 \mathrm{~min}$. The supernatant was recovered and centrifuged at $300 \times g$ for $20 \mathrm{~min}$. Remaining erythrocytes were lysed with distilled water for $40 \mathrm{~s}$, followed by isotonic reconstitution, washing, and resuspension in PBS containing $0.05 \%$ BSA but lacking divalent cations. PMN used in all experiments were $>95 \%$ pure. Cell viability after preparation, which was determined either by the classical trypan blue dye exclusion test or with the Live/Dead Eukolight cell viability kit (see below), was $\geq 99 \%$ in all experiments. All cell preparations were kept on ice until use.

Determination of noncytotoxic porin concentrations. In our previous study we demonstrated that porins associate with the cell membranes after incubation with phagocytic cells (46). However, depending on the concentration used, porin can alter cell morphology and cell viability in vitro (data not shown). Furthermore, we recently showed that prolonged incubation $(15 \mathrm{~h})$ of eukaryotic cell lines with neisserial porin at concentrations of $5 \mu \mathrm{g} / \mathrm{ml}$ or more induces apoptosis (47). Thus, noncytotoxic concentrations of our porin preparation were estimated by incubating PMN or PBMC $\left(4 \times 10^{6}\right.$ cells $\left./ \mathrm{ml}\right)$ in PBSA for 15 min at $37^{\circ} \mathrm{C}$ with various porin concentrations (ranging from 0.1 to $20 \mu \mathrm{g} / \mathrm{ml}$ ). The cells were then stained for $10 \mathrm{~min}$ as indicated in the protocol of the Live/Dead Eukolight viability-cytotoxicity kit (Molecular Probes, Eugene, Oreg.). Dead and live cells were quantified by flow cytometry on a Becton Dickinson FACSort cytometer using PBSA-suspended cells untreated with porin as controls for live cells and using fixed cells as controls for dead cells. Incubation with porin concentrations of $<5 \mu \mathrm{g} / \mathrm{ml}$ or with corresponding dialysis buffer containing detergent concentrations of $<0.0002 \%$ have no measurable effect on the cell viability in all experiments, and these concentrations were subsequently used in the assays.
Determination of lysosomal enzyme release. The release of the lysosomal enzymes, elastase and $\beta$-glucuronidase, by cytochalasin B-treated $(2.5 \mu \mathrm{g} / \mathrm{ml} ; 20$ min, $\left.37^{\circ} \mathrm{C}\right)$ and FMLP $(10$ and $100 \mathrm{nM})$-stimulated PMN $\left(4 \times 10^{6}\right.$ cells $\left./ \mathrm{ml}\right)$ were measured photometrically. Elastase and $\beta$-glucuronidase contents in the supernatants were determined using the method described by Härter et al. (30). Lysosomal enzyme release by stimulated cells was expressed as a percentage of the total release represented by detergent-treated PMN lysates prepared with hexadecyltrimethyl-bromide ammonium (100\% value). The spontaneous release of untreated cells was measured in parallel and did not exceed $1.0 \%$ of the total release.

Measurement of oxidative metabolism by CL. Neutrophils activation were determined by CL measuring continuously produced and released ROS. The chemiluminogenic substrate luminol (5-amino-2,3-dihydro-1,4-phtalazinedione; Sigma) or lucigenin ( $9,9^{\prime}$-bis- $N$-methylacridinium nitrate; Boehringer Mannheim) were used to amplify the CL. CL was measured at constant temperature $\left(37^{\circ} \mathrm{C}\right)$ by a six-channel Biolumat LB9505 (Berthold) equipped with temperature-controlled chambers. All reagents and cell suspensions were brought to $37^{\circ} \mathrm{C}$ before starting the CL measurement. A total of $10^{5}$ cells were suspended in each polystyrene tube filled with $400 \mu \mathrm{l}$ of PBSA containing $5 \mathrm{mM}$ glucose, $1 \mathrm{mM}$ $\mathrm{MgCl}_{2}, 0.5 \mathrm{mM} \mathrm{CaCl}_{2}$, and $100 \mu \mathrm{M}$ luminol or lucigenin. Porin $(0.1$ to $3 \mu \mathrm{g} / \mathrm{ml})$ or the respective dilution of the dialysis buffer containing the same amount of detergent present in the porin fraction (further designated as buffer control) was added to the cells, and CL was measured for 3 to $5 \mathrm{~min}$ without stimulation to determine the background level. Cells were then stimulated by adding (i) $4-\mu 1$ latex beads (Difco; $9 \times 10^{7}$ particles $/ \mathrm{ml}, 0.81 \mu \mathrm{m}$ in diameter), (ii) $100 \mu \mathrm{g}$ of opsonized Zymosan A (Sigma) per $\mathrm{ml}$ boiled for $60 \mathrm{~min}$ at $95^{\circ} \mathrm{C}$ and incubated with $2 \%$ pooled human AB serum, (iii) $100 \mathrm{nM}$ FMLP (Sigma), or (iv) $1 \mu \mathrm{g}$ of PMA (Sigma) per ml. Each concentration described above was optimal for neutrophil stimulation as determined as in pilot CL assays. In some experiments, cells were preincubated with $2.5 \mu \mathrm{g}$ of cytochalasin B (Sigma) per $\mathrm{ml}$ for $20 \mathrm{~min}$ at $37^{\circ} \mathrm{C}$ to increase the $\mathrm{CL}$ of neutrophils in response to the soluble agonist FMLP. For the studies with N. gonorrhoeae-induced CL, as well as for the phagocytosis assay (see below), we used recombinant, nonpiliated gonococcal strain MS11-N309 ( $\mathrm{P}^{-}$, P.IB, Opa $\left.{ }_{52}\right)$ grown on GC agar plates supplemented with erythromycin $(7 \mu \mathrm{g} / \mathrm{ml})$ and kanamycin $(10 \mu \mathrm{g} / \mathrm{ml})$ at $37^{\circ} \mathrm{C}$ as previously described by Kupsch et al. (38). For the phagocytosis assay and the induction of CL, we used a bacterium/neutrophil cell ratio of 50:1

Whether porin itself could stimulate an oxidative burst from neutrophils or PBMC was examined using concentrations of up to $3 \mu \mathrm{g} / \mathrm{ml}$ of porin. In all experiments luminol-enhanced CL in unstimulated, porin-treated cells was similar to the background levels obtained from unstimulated untreated cells, indicating that porin does not induce an oxidative response in phagocytes (see Fig. 2 and 3). To test whether the detergent present in the porin solution could influence the neutrophil responses, cells were preincubated in parallel with PBSA only and then FMLP stimulated. The CL responses of PBSA-suspended cells were indistinguishable from those incubated with PBSA containing low amounts $(0.0002$ to $0.001 \%$ ) of LDAO (data not shown).

Determination of phagocytic activity. The phagocytosis assay with latex beads was performed according to a method described previously (50). Latex Fluoro Spheres (avidin-labeled, $1.0 \mu \mathrm{m}$ in diameter, red fluorescent L5333; Molecular Probes) were resuspended in PBSA $\left(1.6 \times 10^{7}\right.$ particles $)$ and briefly sonicated prior to use. The solution was added to PBMC $\left(2 \times 10^{6} / \mathrm{ml}\right)$ and incubated for $30 \mathrm{~min}$ at $37^{\circ} \mathrm{C}$. Cells were then spun down $(300 \times \mathrm{g}, 5 \mathrm{~min})$ through a fetal calf serum (FCS) cushion to remove the excess of noningested latex beads, washed twice, and resuspended in PBS.

Fluorescence microscopy was initially used to check particle engulfment, and this was subsequently quantified by a Becton-Dickinson flow cytometer (FACSort). A monocyte gate was delineated according to forward-side scatter profile such that only fluorescence due to fluorochrome-labeled particles ingested by monocytes would be quantified.

The phagocytosis assay with live gonococci was performed as follows. PMN or adherent monocytes $\left(8 \times 10^{5} / \mathrm{ml}\right)$ were infected by gonococci (cell/bacterium ratio of 1:50, which in pilot experiments was found to give the maximal CL response) and then resuspended and incubated in PBSA for $40 \mathrm{~min}$ at $37^{\circ} \mathrm{C}$. The noningested bacteria were then removed by washing them twice through an FCS cushion at $300 \times g$ for $5 \mathrm{~min}$. Cells were fixed after settling for $1 \mathrm{~h}$ on coverslips coated with poly-L-lysine and then washed twice with PBS before incubation with PBS containing $0.2 \%$ BSA for $5 \mathrm{~min}$. To stain the intracellular bacteria, the cells were permeabilized with PBS containing $0.1 \%$ Triton X-100 for $10 \mathrm{~min}$, washed twice, blocked for $5 \mathrm{~min}$ in PBS containing $0.2 \%$ BSA, and incubated for $1 \mathrm{~h}$ with a rabbit antiserum specific for gonococcal surface antigens. The cells were then washed three times and incubated with a goat anti-rabbit immunoglobulin $G$ (IgG) antibody conjugated with Texas Red SC for $1 \mathrm{~h}$. After an intense washing, incubation with goat anti-rabbit IgG conjugated with Cy5 mixed with fluorescein isothiocyanate-labeled phalloidin followed. The coverslips were then transferred to slides with a drop of embedding medium. The samples were subjected to confocal microscopy, and the numbers of extra- and intracellular bacteria were counted in fields containing 50 to 60 individual cells. 


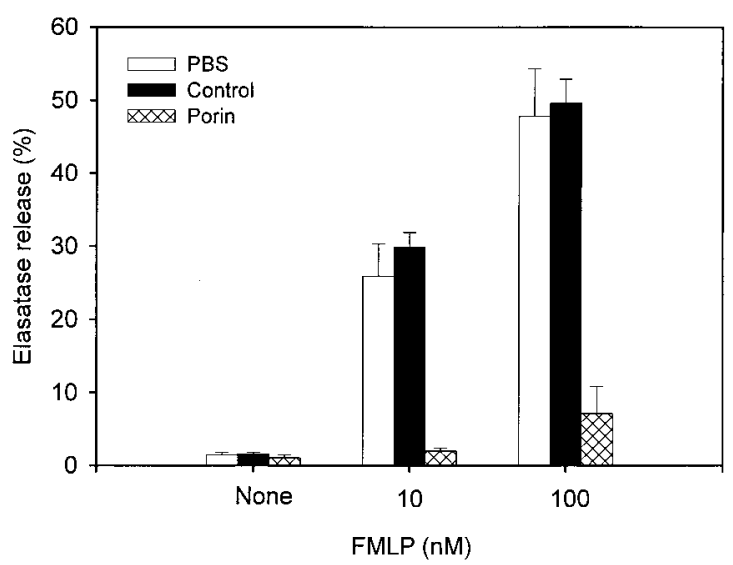

FIG. 1. Effect of porin on FMLP-induced elastase release of human PMN. Cytochalasin B-exposed PMN were incubated with porin for $5 \mathrm{~min}$ or the corresponding buffer control (see Materials and Methods) and then stimulated with FMLP (10 or $100 \mathrm{nM})$. After additional $30 \mathrm{~min}$, the supernatants were recovered and assayed for elastase activity in untreated (PBS) and treated neutrophil cultures. The results are expressed as percentage of the total release obtained from detergent-treated PMN. The data represent the mean \pm the standard deviation of three independent experiments with cells derived from three different donors.

\section{RESULTS}

Effect of porin on elastase release. An important response upon stimulation of neutrophils is the release of lysosomal enzymes, such as elastase, from azurophilic granules. Neisserial porin has been previously found to inhibit neutrophils exocytosis $(8,29)$. Consequently, we assessed the ability of our porin and LPS preparations to impair the release of lysosomal enzymes. The effect of porin on the release of elastase was examined in cytochalasin B-treated PMN stimulated with the soluble bacterial agonist FMLP. Cytochalasin B abrogates microfilament assembly and thus blocks phagolysosome formation, causing lysosomal contents to be exclusively released to the extracellular space. Incubation with $1 \mu \mathrm{g}$ of porin per $\mathrm{ml}$ resulted in a decrease of elastase release in response to both optimal and suboptimal concentrations of FMLP, unlike incubation with the detergent-containing buffer (buffer control) alone (Fig. 1). Control experiments showed that incubation of neutrophils with gonococcal LPS under similar conditions did not inhibit the FMLP-induced elastase release (data not shown). The release of $\beta$-glucuronidase is also significantly reduced by porin treatment (data not shown). These observations confirm the previously published data of Haines and coworkers indicating that gonococcal porin could inhibit granule exocytosis from FMLP-stimulated neutrophils (29).

Effect of porin on PMN oxidative response to FMLP. Treatment of PMN with cytochalasin B also strengthens the respiratory burst in response to FMLP compared to untreated cells stimulated with FMLP alone (Table 1 and reference 53). This phenomenon was employed to determine whether porin could affect the generation of reactive oxygen metabolites in human PMN. Thus, PMN treated with both cytochalasin B and porin were stimulated with FMLP, and both the luminol-enhanced $\mathrm{CL}$ and the lucigenin-enhanced CL were measured. While porin treatment resulted in a dose-dependent inhibition of luminol-enhanced CL (Fig. 2), no or only a slight decrease in the lucigenin-enhanced CL was observed (Table 1). Thus, exogenously added porin appears to act predominantly on exocytosis-associated ROS formation without inhibiting the NADPH-oxidase activity. No inhibition of FMLP-stimulated
TABLE 1. Effect of porin $(1 \mu \mathrm{g} / \mathrm{ml})$ on lucigenin- and luminolenhanced CL in untreated and cytochalasin B-treated neutrophils stimulated by FMLP

\begin{tabular}{lccc}
\hline & & \multicolumn{2}{c}{$\mathrm{CL}\left(\mathrm{cpm}\left[10^{-6}\right] \pm \mathrm{SEM}\right)^{c}$} \\
\cline { 3 - 4 } Treatment $^{a}$ & $\begin{array}{c}\mathrm{FMLP}^{b} \\
(100 \mathrm{nM})\end{array}$ & $\begin{array}{c}\text { Lucigenin } \\
\left(\mathrm{O}_{2}^{-} \text {generation }\right)\end{array}$ & $\begin{array}{c}\text { Luminol } \\
\left(\mathrm{H}_{2} \mathrm{O}_{2} / \mathrm{HOCl} \text { generation }\right)\end{array}$ \\
\hline Buffer control & - & $<0.1$ & $0.3 \pm 0.1$ \\
Buffer control & + & $2.2 \pm 0.4$ & $23.1 \pm 5.5$ \\
Porin & - & $<0.1$ & $0.2 \pm 0.1$ \\
Porin & + & $15.2 \pm 2.6$ & $87.7 \pm 9.4$ \\
CB & - & $<0.1$ & $0.2 \pm 0.1$ \\
CB & + & $8.1 \pm 2.9$ & $154.3 \pm 17.4$ \\
CB + porin & - & $<0.1$ & $<0.1$ \\
CB + porin & + & $6.9 \pm 1.1$ & $73.9 \pm 17.8$ \\
\hline
\end{tabular}

${ }^{a}$ Porin $(1 \mu \mathrm{g} / \mathrm{ml}, 5 \mathrm{~min})$; cytochalasin B only $(\mathrm{CB} ; 2.5 \mu \mathrm{g} / \mathrm{ml})$; cytochalasin B plus porin $(\mathrm{CB}+$ porin; $1 \mu \mathrm{g} / \mathrm{ml}, 5 \mathrm{~min})$.

${ }^{b}$ PMN remained unstimulated $(-)$ or were stimulated after $25 \mathrm{~min}$ of incubation by $100 \mathrm{nM}$ FMLP $(+)$.

${ }^{c}$ Lucigenin- and luminol-amplified CL was monitored for $10 \mathrm{~min}$. The results are expressed as the mean peak $\mathrm{CL} \pm$ the standard error of the mean of three different experiments $(n=3)$ with PMN from different donors.

CL of cytochalasin B-treated PMN was found after treatment with gonococcal LPS (data not shown).

Notably, PMN not treated with cytochalasin B and stimulated with FMLP demonstrate increases in both lucigenin- and luminol-amplified CL when treated with porin (Fig. 3 and Table 1). The ability of an agent to increase neutrophilic responsiveness to unrelated stimuli is a phenomenon known as priming, and it is a well-known property of bacterial LPS $(1,25,37$, $60)$. Nonprimed neutrophils showed only a moderate CL in response to FMLP; however, purified gonococcal LPS at a concentration present in the porin preparation was also able to prime the oxidative burst of neutrophils in response to FMLP (data not shown). The CL response in unstimulated, porintreated and LPS-treated cells was similar to the background level obtained from unstimulated untreated cells, indicating that neither porin nor gonococcal LPS directly induces an oxidative response in human neutrophils (data not shown; Fig. 2 and 3 and Table 1).

Effect of porin on phagocytosis-induced oxidative metabolism of PMN. The uptake of particles leads to rapid acidification of the phagosome and consequently to an increased pro-

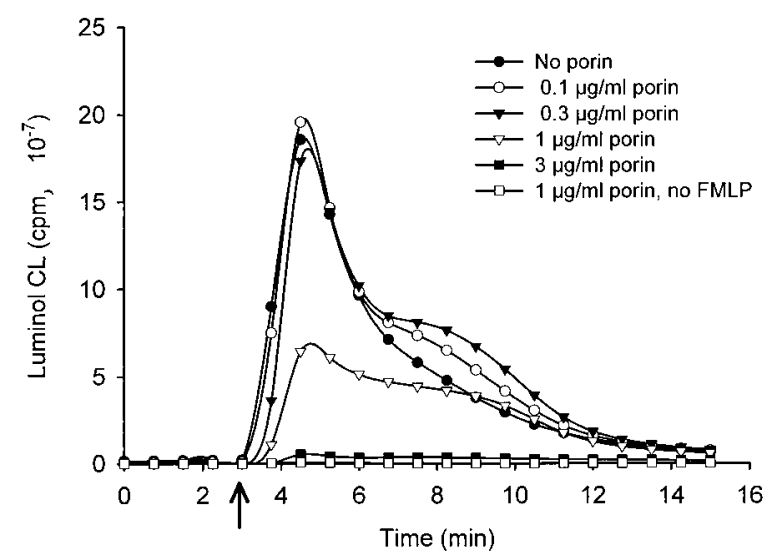

FIG. 2. Effect of porin on the luminol-enhanced CL response to FMLP in cytochalasin B-treated PMN. PMN were treated with cytochalasin B $(2.5 \mu \mathrm{g} / \mathrm{ml}$, $20 \mathrm{~min}$ ) before incubation with different concentrations of porin or the corresponding buffer control for $3 \mathrm{~min}$. CL was stimulated by addition of $100 \mathrm{nM}$ FMLP (see arrow). 

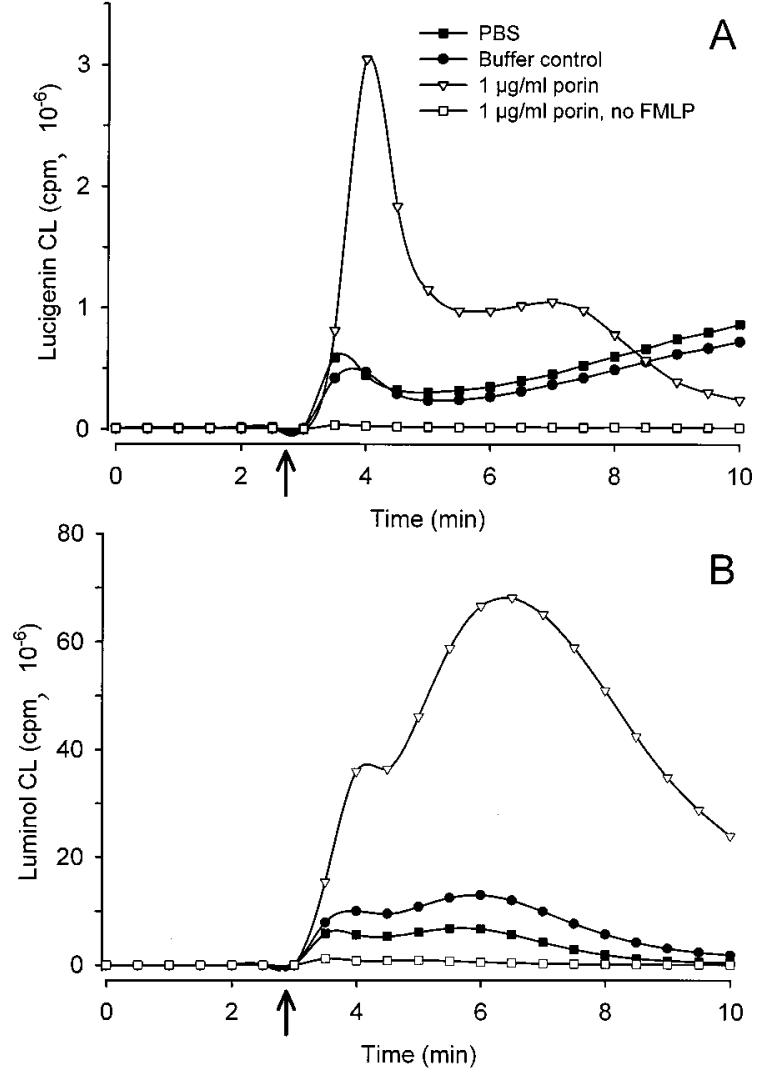

FIG. 3. Effect of porin on neutrophil oxidative response to the activating peptide FMLP. PMNs were preincubated with porin $(1.0 \mu \mathrm{g} / \mathrm{ml})$, with corresponding buffer control, or with PBS for $3 \mathrm{~min}$ and subsequently stimulated by adding $100 \mathrm{nM}$ FMLP to each sample (see arrow). Control cells treated with porin but without FMLP were run in parallel. Shown are representative results of three experiments. (A) Kinetics of lucigenin-enhanced CL of normal PMN. (B) Kinetics of luminol-enhanced CL of normal PMN.

duction of $\mathrm{H}_{2} \mathrm{O}_{2}$ and derivated oxygen species which can be measured by luminol-enhanced CL. The oxidative burst of PMN resulting from stimulation with opsonized zymosan exhibits a remarkable luminol-enhanced CL response, characterized by rapidly increasing CL 5 to $10 \mathrm{~min}$ after addition of zymosan and peaking at between 20 and $30 \mathrm{~min}$ (Fig. 4A). Treatment of PMN with porin results in a significant decrease of this characteristic CL pattern. The effect of porin on luminol-enhanced CL was dose dependent, with $50 \%$ inhibition occurring at a concentration of 1 to $2 \mu \mathrm{gl}$ of porin per $\mathrm{ml}$. When $3 \mu \mathrm{g}$ of porin per $\mathrm{ml}$ is used, the oxidative response is almost completely abrogated. Similar results were obtained when we used PBMC instead of PMN (data not shown). Treatment with porin also markedly inhibited luminol-enhanced CL resulting from stimulating $\mathrm{PMN}$ with nondegradable inert latex particles (Fig. 4B). The inhibitory effect of porin could not be reversed at later time points or by intense washing, suggesting that the protein interacts directly with the cells and irreversibly disturbs their effector mechanisms. In contrast, incubation of PMN with various concentrations of gonococcal LPS, even concentrations of as high as $300 \mathrm{ng} / \mathrm{ml}$, did not inhibit or reduce but rather enhanced neutrophilic responses to zymosan or latex beads (data not shown). Luminol-enhanced CL requires both the presence of oxygen metabolites and the release of active MPO $(2,19)$. When porin $(2$ to $10 \mu \mathrm{g} / \mathrm{ml})$ is mixed with purified MPO $(0.5 \mathrm{U} / \mathrm{ml})$, the luminol-enhanced CL response in a cell-free system containing $3 \mathrm{mM} \mathrm{H}_{2} \mathrm{O}_{2}$ is unal- tered, indicating that porin neither impairs MPO activity nor reacts with the reactive oxygen species oxidizing luminol (data not shown).

Effect of porin on oxidative metabolism induced by Ngo. Uptake of nonopsonized gonococci by PMN depends on the expression of a particular opacity protein. This protein binds to a member of the CD66 protein family on the PMN cell surface, and this in turn stimulates phagocytosis and an oxidative response $(12,24) . \mathrm{Opa}_{52}{ }^{+}$, a nonpiliated gonococcal strain expressing this opacity protein, was used to examine the effect of porin on the oxidative response induced by gonococci. Neutrophils were pretreated for $5 \mathrm{~min}$ with different concentrations of porin or, as a control, with detergent containing buffer diluted with PBS (buffer control), after which the CL response was induced by adding $\mathrm{Opa}_{52}{ }^{+}$gonococci at multiplicity of infection of 50 .

Gonococci added to an in vitro culture of PMN only induced a significant luminol-enhanced, but not a lucigenin-enhanced, CL. Kinetic studies show that the bacteria, in the absence of porin, immediately cause an increase of luminol-enhanced CL, which rises gradually to peak after 30 to $40 \mathrm{~min}$. Incubation of the cells with porin reduced this response in a dose-dependent manner (Fig. 5A). Inhibition of the response was observed at porin concentrations of $>0.4 \mu \mathrm{g} / \mathrm{ml}$ and was complete after treatment with $\geq 3 \mu \mathrm{g}$ of porin per $\mathrm{ml}$.
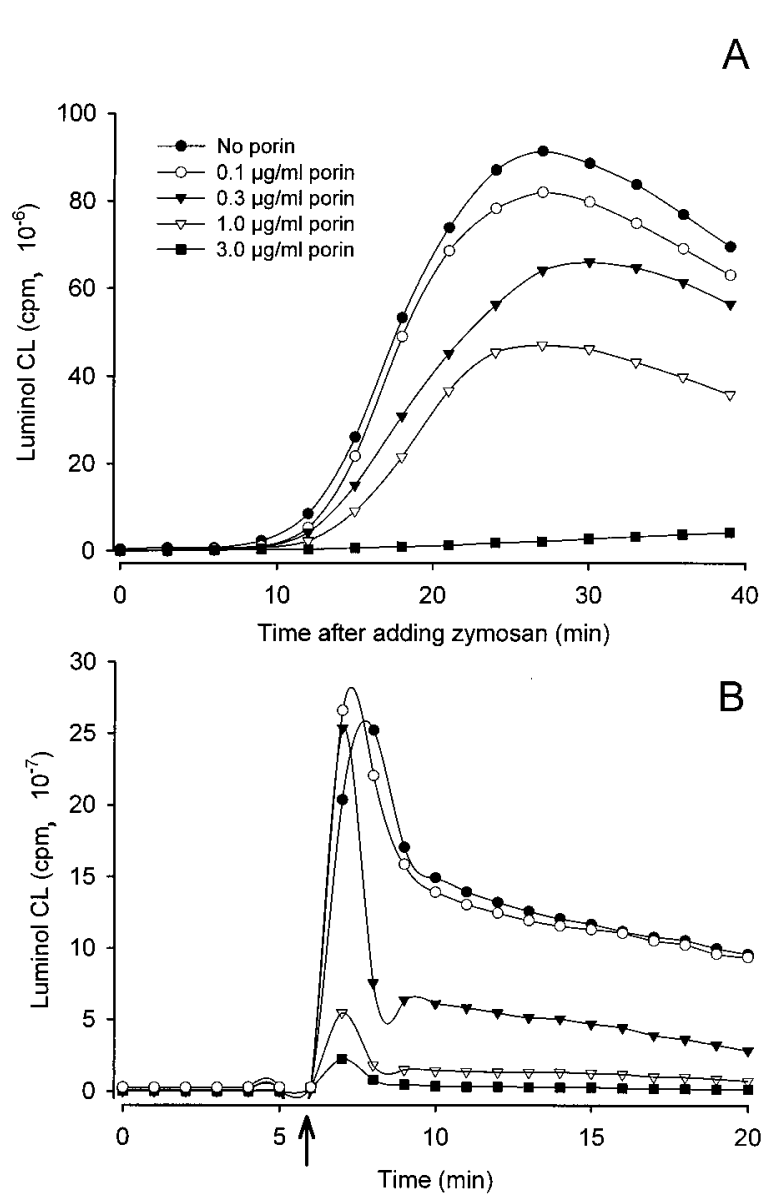

FIG. 4. Luminol-enhanced CL of human PMN treated with gonococcal porin. PMN were incubated with different concentrations of porin and then stimulated by adding either zymosan (A) or latex beads (B). An arrow marks the point at which latex beads were added. The data shown are from one of three experiments, all of which gave similar results. 
A

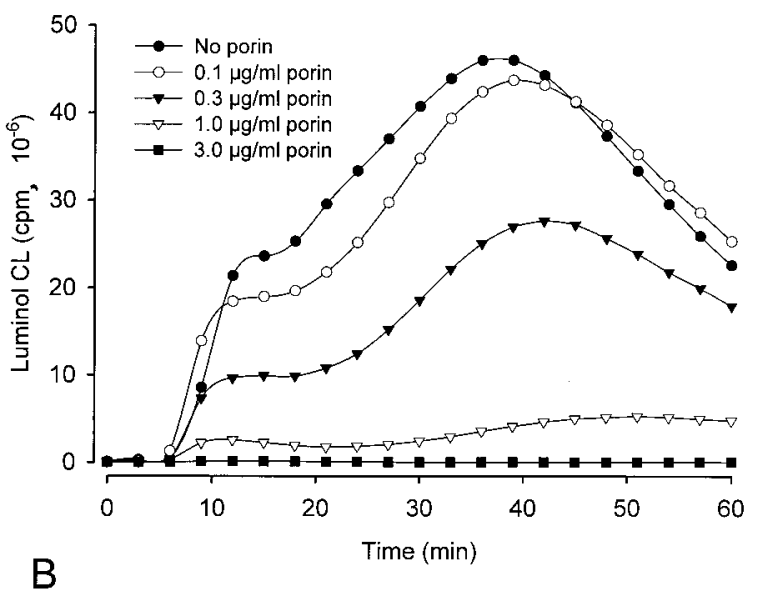

B

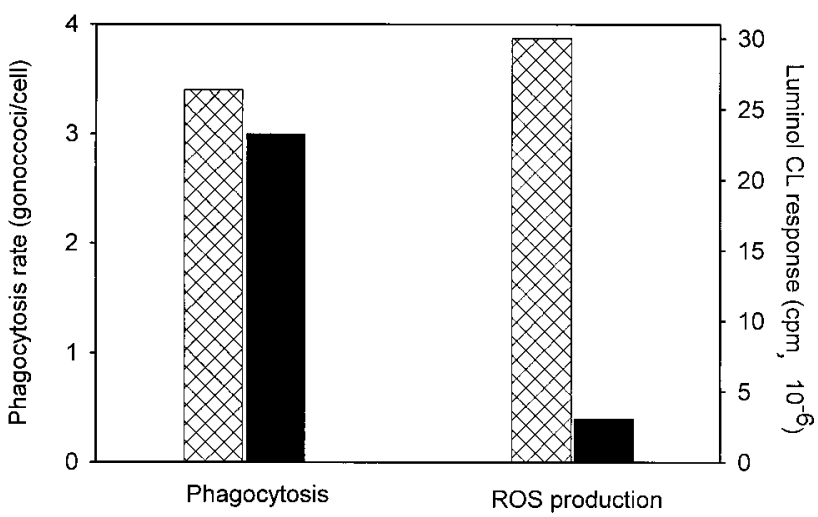

FIG. 5. Effect of porin on the oxidative burst and phagocytic activity of PMN induced by viable gonococci. (A) Luminol-enhanced CL of normal PMN in response to invasive $\mathrm{Opa}_{52}$ gonococci. $\mathrm{PMN}$ were preincubated with increasing concentrations of porin before bacteria were added. Cells in the absence of bacteria were also tested but gave no signal (data not shown). The graph shows the results of one representative experiment out of three total. (B) Phagocytic activity occurring in parallel with the CL response. PMN were exposed to $\mathrm{Opa}_{52}{ }^{+}$gonococci in the absence (hatched columns) or presence (black columns) of porin. Shown are the results of a representative experiment with phagocytosis and CL assays performed in parallel using PMN from one donor.

The porin-mediated inhibition of $\mathrm{Opa}_{52}{ }^{+}$gonococcus-induced CL is not due to a decrease in the phagocytic activity of the treated PMN, as shown by the enumeration of the ingested bacteria by confocal scanning microscopy and flow cytometry (Fig. 5B). These experiments were performed in parallel with the CL assay. PMN phagocytosis of $\mathrm{Opa}_{52}{ }^{+}$gonococci was similar whether or not they had been incubated with porin at concentrations that inhibited CL $(1.0 \mu \mathrm{g} / \mathrm{ml})$. Thus, the porinmediated inhibition of the luminol CL response to gonococci was not the result of a loss of the phagocytic activity of these cells.

Effect of porin on the phagocytic activity and oxidative metabolism of peripheral monocytes. The effect of porin on PBMC phagocytosis was tested by utilizing fluorochrome-labeled latex beads. PBMC pretreated with porin (1 to $2 \mu \mathrm{g} / \mathrm{ml}$ ) were exposed to optimal doses of these particles and, after incubation and washing to remove free particles, the uptake of the beads by the cells was determined by flow cytometry. Analysis of 20,000 cells gave results similar to our microscopic observations, namely, that porin treatment did not alter the number of cells ingesting the particles, nor the number of particles ingested per cell (Fig. 6A). Notably, although $>90 \%$ of the monocytes were intact after treatment with porin concentrations lower than $5 \mu \mathrm{g} / \mathrm{ml}$, porin concentrations higher than $5 \mu \mathrm{g} / \mathrm{ml}$ caused the monocytes to lyse if they had ingested more than 10 beads. This suggests that porin integrated in the plasma membrane in combination with latex beads causes the cells to become more fragile.

Latex particles induced a strong luminol CL response in
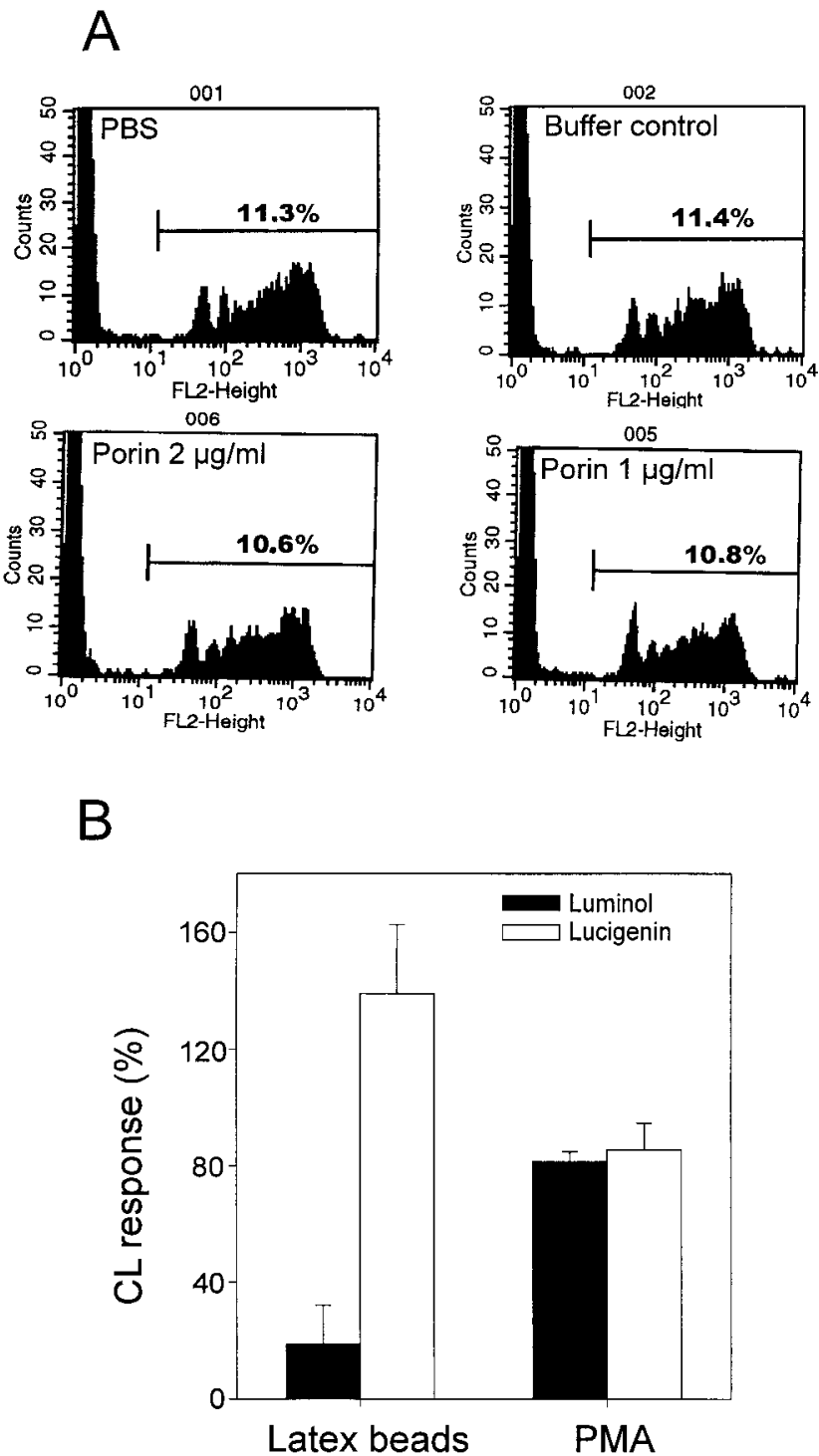

FIG. 6. Effect of porin on PBMC phagocytosis and luminol- and lucigeninenhanced CL. (A) Phagocytosis of fluorescent latex beads. Beads were added to untreated (PBS) or PBMC-treated with 1 or $2 \mu \mathrm{g}$ of porin per $\mathrm{ml}$ or a corresponding buffer control. After the removal of noningested beads, samples were analyzed by using FACSort. Phagocytic cells, which had ingested latex beads, were visualized by an increase in fluorescence intensity. Cells without beads were also analyzed and showed no fluorescence in the above-marked region (data not shown). (B) Luminol- and lucigenin-enhanced CL response to latex beads. PBMC were treated with porin prior to stimulation with latex beads. CL amplified by luminol or lucigenin was measured in five separate assays and the results are expressed as \% of CL activity ( \pm The standard error of the mean) of the relevant control (cells treated with stimulators in the absence of porin and set as $100 \%$ ). The control means of the five experiments were as follows: luminol plus latex, $(20.27 \pm$ $15.3) \times 10^{7} \mathrm{cpm}$; lucigenin plus latex, $(3.74 \pm 2.3) \times 10^{7} \mathrm{cpm}$; luminol plus PMA, $(36.12 \pm 14.3) \times 10^{7} \mathrm{cpm}$; and lucigenin plus PMA, $(18.73 \pm 9.7) \times 10^{7} \mathrm{cpm}$. 
PBMC characterized by a rapid rise and fall of luminescence in the first $2 \mathrm{~min}$. Despite the lack of effect of porin on PBMC phagocytosis, porin decreased the luminol-enhanced CL response of PBMC stimulated with latex particles (Fig. 6B). The parallel measurement of $\mathrm{O}_{2}{ }^{-}$production by lucigenin-amplified CL, however, showed that porin treatment in fact enhanced the $\mathrm{CL}$ response to latex particles, indicating that PBMC, in principle, can respond with $\mathrm{O}_{2}{ }^{-}$generation upon porin treatment. This is further supported by the finding that porin has negligible effects on the oxidative metabolism of PBMC, which are stimulated with the phorbolester PMA that directly activates protein kinase $\mathrm{C}$ (PKC).

\section{DISCUSSION}

We show here that gonoccocal porin modifies the oxidative burst cascade of phagocytic cells. The level of reactive oxygen generated by phagocytes was assayed by CL measurements using lucigenin or luminol. Lucigenin-amplified CL predominantly monitors the initial $\mathrm{O}_{2}{ }^{-}$production, whereas luminol is a suitable substrate to measure reactions linked to the release of lysosomal MPO into the surrounding medium $(2,19,23,43)$. Porin-treated PMN showed a reduction in luminol-enhanced CL when they were stimulated with zymosan, latex particles, gonococci, or cytochalasin B plus FMLP (Fig. 4 and 5). However, lucigenin CL in response to FMLP was not inhibited, suggesting that assembly of NADPH oxidase with the subsequent production of $\mathrm{O}_{2}{ }^{-}$was not affected by porin treatment (Table 1). Porin treatment inhibited also luminol-dependent CL in peripheral blood monocytes exposed to latex particles, whereas the lucigenin-enhanced CL was again not inhibited (Fig. 6). These results suggest that porin particularly modifies MPO-dependent reactions of the oxidative metabolism of phagocytes which are important for the conversion of peroxide into chlorinated reactive oxygen species (36). Furthermore, it is generally accepted that these MPO-derived ROS exert most of the bactericidal effects, since defective degranulation of MPO leads to impaired microbial killing by neutrophils and to increased susceptibility to infection $(26,33,40,44)$. In this regard porin may affect the bactericidal activity of phagocytic cells by impairing the formation of highly toxic oxidants.

The infection by $N$. gonorrhoeae is characterized by a massive infiltration of activated neutrophils into the infected tissues (54). We and others showed that gonococci added to neutrophils induced an oxidative response, depending on the opacity protein expressed on the bacterial surface $(12,24)$. We could only measure the intracellular oxidative burst induced by gonococci as luminol-enhanced CL and not as lucigenin-enhanced CL. This observation is consistent with the findings by Naids and Rest (48), who showed that gonococci induce an oxidative response in neutrophils without generating $\mathrm{O}_{2^{-}}$and $\mathrm{H}_{2} \mathrm{O}_{2}$ in the extracellular milieu. Moreover, gonococci are not very sensitive to these primary products of the oxidative burst since the oxidative stress upregulates gonococcal catalase, which then rapidly detoxifies extracellularly released $\mathrm{H}_{2} \mathrm{O}_{2}(3$, 62). Bactericidal ROS such as $\mathrm{HOCl}$, however, is formed by MPO-dependent reactions in the phagolysosome. That PMNs treated with porin showed a decreased luminol-enhanced CL in response to stimulation with gonococci begs the question: why do gonococci, which bear porin, stimulate luminol-enhanced CL in the first place? Neisserial porin was shown previously to be able to translocate from the bacterial cell surface to target cell membranes by an as-yet-undefined mechanism (10). Thus, it is possible that phagocytosed gonococci suppress the formation of ROS only locally, where porin is inserted into the phagosome membrane. Another possibility is that the en- gulfed gonococci, although they die during the process, act in an altruistic fashion to downregulate PMN activity for gonococci still free in the local vicinity. That gonococci induce a strong luminol-enhanced CL despite their own delivery of porin to PMN is probably best explained by assuming a localized effect of porin. In contrast to purified porin, which contacts the whole-cell surface and is probably taken up into vesicular compartments, gonococci touch the cell surface only at small discrete areas and are rapidly engulfed by the PMN. Hence, it is conceivable that these bacteria are protected from the action of MPO despite triggering the release of this enzyme from the secondary granula. This view is consistent with recent microscopic observations of our group indicating the depletion of certain lysosomal marker proteins upon gonococcal infection of phagocytes (Hauck et al., in preparation).

We did not observe a reduced phagocytic activity after treatment with porin preparation, since PBMC phagocytosis of latex beads was not altered after porin treatment. Further, the ability of PMN to engulf live gonococci was also not affected by porin treatment. In contrast to this, Bjerknes et al. (8) reported that neisserial porins, including the gonococcal porin PIB, inhibits actin polymerization and bacterial uptake. The discrepancy between our findings and their results cannot be clarified definitively and may be best explained by the different pathways by which phagocytes incorporated the bacteria in the respective studies. Bjerknes et al. (8) determined the phagocytosis of meningococci by neutrophils in the presence of human serum. Thus, the engulfment of the bacteria was obviously triggered by $\mathrm{Fc}$ receptor-dependent mechanisms. In our study we used recombinant, $\mathrm{Opa}_{52}$-expressing gonococci to measure phagocytic activity. The phagocytosis of $\mathrm{Opa}_{52}$ gonococci by neutrophils do not require opsonization by antibodies. The gonococcal $\mathrm{Opa}_{52}$ protein directly interacts through CD66 receptors on PMN triggering their rapid engulfment (24).

The observation that porin did not alter the phagocytic activity indicates that the reduction in luminol-enhanced CL was not due to porin-mediated inhibition of bacterial phagocytosis. Furthermore, that porin directly inhibits MPO is also unlikely since porin did not impair the enzymatic activity of purified MPO in a cell-free system containing luminol. It is rather likely that porin inhibits the exocytosis of MPO from azurophilic granules, as has been previously postulated $(8,28)$. This is supported by our finding that porin inhibited the release of elastase, which is a marker enzyme of azurophilic granules. This also confirms prior observations that porin inhibits degranulation in activated phagocytic cells. (8, 27-29). One mechanism whereby degranulation may be inhibited is a defect in phagolysosomal fusion. If porin inhibits phagolysosomal fusion, MPO release would be impaired. That porin can indeed inhibit phagolysosome fusion has been suggested by our previous studies (46) and also by our work with cytochalasin Btreated PMN stimulated by FMLP. Cytochalasin B abrogates intracellular phagolysosome generation but not the lysosome fusion with the plasma membrane. Consequently, cytochalasin B-treated PMN predominantly degranulate their lysosomal contents into the extracellular medium and have an enhanced oxidative response after stimulation with FMLP $(32,53)$.

Using this test system Haines and coworkers (29) showed that porin does not affect the assembly of NADPH-oxidase responsible for the $\mathrm{O}_{2}{ }^{-}$generation, a finding which is supported by our experiments with lucigenin-enhanced CL by cytochalasin B-treated PMN after FMLP stimulation (Table 1). In contrast, PMN showed a decreased luminol-enhanced CL after treatment with cytochalasin B and porin. These results are in agreement with the hypothesis of Haines et al. (28), who suggested that gonococcal porin interferes with the intra- 
cellular signaling events of neutrophils. Stimulation of phagocytes with FMLP leads to the activation of $\mathrm{G}$ protein-coupled receptors and phospholipase $\mathrm{C}$, resulting in the cleavage of phosphatidylinositol into inositol triphosphate (IP3) and diacylglycerol (DG). Both, IP3 and DG, modulate the subsequent release of $\mathrm{Ca}^{2+}$ from intracellular stores. $\mathrm{Ca}^{2+}$ in association with DG activates PKC, which triggers changes in diverse cellular functions (52). Concomitantly, the cells undergo changes in ion movements and intracellular $\mathrm{pH}$. Neutrophils respond to FMLP with a biphasic rise in DG, and each DG peak correlates to a distinct function in cellular signaling $(28,52,53)$. Whereas the first, so-called "early" DG peak mainly "triggers" the neutrophils and upregulates their superoxide anion production, the second "late" DG rise is responsible for the activation and promotes the degranulation process $(27,52)$. It has been reported that porin selectively blocks phosphocholin phospholipase $\mathrm{C}$ and in turn diminished the late $\mathrm{DG}$ generation but had no effect on the early DG generation caused by the cleavage of phosphatidylinositol by phosphoinositol phospholipase C $(27,28)$. In these studies it was assumed that the signal represented by the late DG is required for degranulation while the early peak is sufficient for activation of the NADPH oxidase. In contrast, cytochalasin B is considered to increase the late phase of DG (52). Hence, porin treatment antagonizes with cytochalasin $\mathrm{B}$, resulting in a dose-dependent inhibition of degranulation-dependent formation of ROS, as was shown here by the inhibition of luminol-enhanced CL response.

In the studies of Bjerknes and coworkers (8), neisserial porins were found to prime neutrophils to increase their oxidative burst. We also showed that porin treatment increased both luminol- and lucigenin-enhanced CL in response to FMLP but, in contrast to the previous study, only when neutrophils were not treated with cytochalasin B. An optimal oxidative burst by normal neutrophils stimulated with FMLP requires a priming agent, since unprimed normal PMN produce only few oxygen radicals when exposed to FMLP $(1,51)$. The respiratory burst of primed PMN activated under these conditions consists of an initial phase with high rates of $\mathrm{O}_{2}{ }^{-}$generation and $\mathrm{H}_{2} \mathrm{O}_{2}$ release and a second, more-sustained phase of ROS production and luminol-enhanced CL (Fig. 3 and references 7, 11, and 15). LPS directly affects the function of neutrophils by upregulating several receptors and by augmenting the respiratory burst and secretion of lysosomal enzymes $(25,37,60)$. Since the native porin preparation always contains residual amounts of gonococcal endotoxin, we included LPS as a control in our assays. Indeed, we found that purified gonococcal LPS at the same concentration as in our porin fraction was also able to prime normal PMN to increase their oxidative response. Interestingly, the priming effect of gonococcal LPS was observed in the absence of human serum. Human serum contains the LPS binding protein which, in turn, interacts with CD14, a protein expressed on the surface of monocytes and neutrophils. Thus, our results indicate that gonococcal LPS at concentrations of $>100 \mathrm{ng} / \mathrm{ml}$ may not utilize the CD14 receptor to stimulate the phagocytes. This finding is consistent with previous published results in which under certain circumstances phagocytes can also respond to a high dose of LPS in a CD14-independent manner $(22,31)$. Bjerknes and coworkers $(8)$ showed that blocking the receptor for the LPS-binding protein present in human serum using a saturating concentration of anti-CD14 antibodies does not prevent the priming effect of porin, suggesting that porin and not LPS was responsible for the priming effect on neutrophils. In that study, however, porin was contained in a different detergent and was probably less contaminated with LPS.

LPS is considered to favor the trimerization of gonococcal porin and to be essential for the insertion of porin into mem- branes as was previously reported for the Escherichia coli outer membrane protein PhoE $(13,34)$. However, endotoxin-associated proteins are known to be potent stimuli for human phagocytes (9). Thus, we favor an explanation in which LPS facilitates the priming of neutrophils by porin. A role for LPS in porin-associated downregulation of the luminol-enhanced CL response can be excluded unlikely since this response was reduced only by porin and not by LPS. Cells treated with gonococcal LPS even showed an increased extracellular release of ROS after phagocytosis of zymosan, a finding which is consistent with observations made by Follin and Dahlgren (20).

Porins from other gram-negative species have also been shown to be able to stimulate and modulate the cellular responses of neutrophils and mononuclear cells. Tufano and coworkers showed that porins from Yersinia enterocelitica and Helicobacter pylori bind to PMN and that this results in altered cell morphology, reduced surface hydrophobicity, and adherence, accompanied by a reduction of oxidative burst and chemotaxis $(56,57)$. These studies also showed, as we did for gonococcal porin, that the porins of these organisms may inhibit granule exocytosis and the subsequent release of reactive oxygen metabolites. This downstream formation of $\mathrm{O}_{2}{ }^{-}$-derived oxidants are dependent on the MPO activity $(18,26)$. This function of porin may be an escape strategy of facultative intracellular bacteria to circumvent both oxygen-dependent and -independent killing mechanisms by phagocytes. Our recent studies further demonstrate that the porin is associated with the induction of apoptosis by the Neisseria gonorrhoeae (47). Thus, porin evidently interferes in multiple ways with the physiology of infected cells and therefore probably plays a central role in the infection process of this pathogenic species.

\section{ACKNOWLEDGMENTS}

This work was supported in part by a grant of the Fonds der Chemischen Industrie to T.F.M.

We thank Christa Lanz, Ilona Harm, Petra Lindenberg, and Elke Ziska for their expert assistance and Martin Ernst (Forschungszentrum Borstel) for helpful discussions.

\section{REFERENCES}

1. Aida, Y., and M. J. Pabst. 1990. Priming of neutrophils by lipopolysaccharide for enhanced release of superoxide. Requirement for plasma but not for tumor necrosis factor-alpha. J. Immunol. 145:3017-3030.

2. Albrecht, D., and T. W. Jungi. 1993. Luminol-enhanced chemiluminescence induced in peripheral blood-derived human phagocytes: obligatory requirement of myeloperoxidase exoocytosis by monocytes. J. Leukoc. Biol. 54: 300-306.

3. Alcorn, T. M., H. Y. Zheng, M. R. Gunther, D. J. Hassett, and M. S. Cohen. 1994. Variation in hydrogen peroxide sensitivity between different strains of Neisseria gonorrhoeae is dependent on factors in addition to catalase activity. Infect. Immun. 62:2138-2140.

4. Allen, R. C. 1986. Phagocytic leukocyte activities and chemiluminescence: a kinetic approach to analysis. Methods Enzymol. 133:449-493.

5. Bauer, F. J., T. Rudel, M. Stein, and T. F. Meyer. 1999. Mutagenesis of the Neisseria gonorrhoeae porin reduces invasion in epithelial cells and enhances phagocyte responsiveness. Mol. Microbiol. 31:903-913.

6. Belland, R. J., T. Chen, J. Swanson, and S. H. Fischer. 1992. Human neutrophils response to recombinant neisserial Opa proteins. Mol. Microbiol. 6:1729-1737.

7. Bender, J. G., and D. van Epps. 1983. Analysis of the bimodal chemiluminescence pattern stimulated in human neutrophils by chemotactic factors. Infect. Immun. 41:1062-1070.

8. Bjerknes, R., H. K. Guttormsen, C. O. Solberg, and L. M. Wetzler. 1995. Neisserial porins inhibit human neutrophil actin polymerisation, degranulation, opsonin receptor expression, and phagocytosis but prime the neutrophils to increase their oxidative burst. Infect. Immun. 63:160-167.

9. Bjornson, B. H., E. Agura, J. M. Harvey, M. Johns, R. G. Andrews, and W. R. McCabe. 1988. Endotoxin-associated protein: a potent stimulus for human granulocytopoietic activity which may be accessory cell independent. Infect. Immun. 56:1602-1607.

10. Blake, M. S., and E. C. Gotschlich. 1983. Gonococcal membrane proteins: Speculation on their role in pathogenesis. Prog. Allergy 33:298-313. 
11. Briheim, G., O. Stendahl, and C. Dahlgren. 1984. Intra- and extracellular events in luminol-dependent chemiluminescence of polymorphonuclear leukocytes. Infect. Immun. 45:1-5.

12. Chen, T., F. Grunert, A. Medina-Marino, and E. C. Gotschlich. 1997. Several carcinoembryonic antigens (CD66) serve as receptors for gonococcal opacity proteins. J. Exp. Med. 185:1557-1564.

13. de Cock, H., and J. Tommassen. 1996. Lipopolysaccharides and divalent cations are involved in the formation of an assembly-competent intermediate of outer-membrane PhoE of E. coli. EMBO J. 15:5567-5573.

14. Dahlgren, C., H. Aniansson, and K.-E. Magnusson. 1985. Pattern of formylmethionyl-leucyl-phenylalaline-induced luminol- and lucigenin-dependent chemiluminescence in human neutrophils. Infect. Immun. 47:326-328.

15. Dahlgren, C. 1988 . Effects on extra- and intracellulary localised chemoattractant-induced, oxygen radical production in neutrophils following modulation of conditions for ligand-receptor interaction. Inflammation 12:335-349.

16. Edwards, S. W. 1987. Luminol- and lucigenin-dependent chemiluminescence of neutrophils: role of degranulation. J. Clin. Lab. Immunol. 22:35-39.

17. Edwards, S. W., C. A. Hart, J. M. Davies, J. Pattison, V. Hughes, and J. A. Sills. 1988. Impaired neutrophil killing in a patient with defective degranulation of myeloperoxidase. J. Clin. Lab. Immunol. 25:201-206.

18. Eiserich, J. P., M. Hristova, C. E. Cross, A. Daniel-Jones, B. A. Freeman, B. Halliwell, and A. van der Vliet. 1998. Formation of nitric oxide-derived inflammatory oxidants by myeloperoxidase in neutrophils. Nature 391:393-397.

19. Faulkner, K., and I. Fridovich. 1993. Luminol and lucigenin as detectors for $\mathrm{O}_{2}-$. Free Radical Biol. Med. 15:447-451.

20. Follin, P., and C. Dahlgren. 1992. Phagocytosis by lipopolysaccharide primed human neutrophils is associated with increased extracellular release of reactive oxygen metabolites. Inflammation 16:83-91.

21. Galanos, C., O. Luderitz, and O. Westphal. 1969. A new method for the extraction of R lipopolysacchsride. Eur. J. Biochem. 9:245-249.

22. Gangloff, S. C., N. Hijiya, A. Haziot, and S. M. Goyert. 1999. Lipopolysaccharide structure influences the macrophage response via CD14-independent and CD14-dependent pathways. Clin. Infect. Dis. 28:491-496.

23. Gerber, C. E., S. Kuci, M. Zipfel, D. Niethammer, and G. Bruchelt. 1996. Phagocytic activity and oxidative burst of granulocytes in persons with myeloperoxidase defiency. Eur. J. Clin. Chem. Biochem. 34:901-908.

24. Gray-Owen, S. C., D. R. Lorenzen, A. Haude, T. F. Meyer, and C. Dehio. 1997. Gonococcal Opa proteins have different binding specificities for CD66 receptors expressed on distinct tissue types. Mol. Microbiol 26:971-980.

25. Guthrie, L. A., L. C. McPhail, P. M. Henson, and R. B. Johnson, Jr. 1984. Priming of neutrophils for enhanced release of oxygen metabolites by bacterial lipopolysaccharide. Evidence for increased activity of the superoxideproducing enzyme. J. Exp. Med. 160:1656-1671.

26. Haas, A., and W. Goebel. 1992. Microbial strategies to prevent oxygendependent killing by phagocytes. Free Radical Res. Commun 16:137-157.

27. Haines, K. A., and G. Weissmann. 1990. Protein I of N. gonorrhoeae shows that phosphatide from phosphotidylcholine via phospholipase $\mathrm{C}$ is an intracellular messenger in neutrophil activation by chemoattractants Adv. Prostglandin Thrombaxan Leukotriene Res. 21:545-552.

28. Haines, K. A., J. Reibmann, X. Tang, M. S. Blake, and G. Weissmann. 1991. Effects of protein I of Neisseria gonorrhoeae on neutrophil activation: generation of diacylglycerol from phosphatidylcholine via a specific phospholipase C is associated with exocytosis. J. Biol. Chem. 114:433-442.

29. Haines, K. A., L. Yeh, M. S. Blake, P. Cristello, H. Korchak, and G. Weissmann. 1988. Protein I, a translocatable ion channel from Neisseria gonorrhoeae, selectively inhibits exocytosis from human neutrophils without inhibiting $\mathrm{O}_{2}-$ generation. J. Biol. Chem. 263:945-951.

30. Härter, L., F. Petersen, H.-D. Flad, and E. Brandt. 1994. Connective tissueactivating peptide III desensitizes chemokine receptors on neutrophils. J. Immunol. 153:5698-5708

31. Haziot, A., X. Y. Lin, F. Zhang, and S. M. Goyert. 1998. The induction of acute phase proteins by lipopolysaccharide uses a novel pathway that is CD14-independent. J. Immunol. 160:2570-2572.

32. Hoenycutt, P. J., and J. E. Niedel. 1986. Cytochalasin B enhancement of the diacylglycerol response in formyl peptide-stimulated neutrophils. J. Biol. Chem. 261:15900-15905.

33. Humphreys, J. M., B. Davies, C. A. Hart, and S. W. Edwards. 1989. Role of myeloperoxidase in the killing of Staphylococcus aureus by human neutrophils: studies with the myeloperoxidase inhibitor salicylhydroxamic acid. J. Gen. Microbiol. 135:1187-1193.

34. Jansen, C., M. Heutnik, J. Tommassen, and H. de Cock. 2000. The assembly pathway of outer membrane protein PhoE of Escherichia coli. Eur. J. Biochem. 267:3792-3800.

35. Judd, R. C. 1989 . Protein I: structure, function and genetics. Clin. Microbiol. Rev. 2:S41-S48.

36. Klebanoff, S. J. 1982. Oxygen-dependent cytotoxic mechanism of phagocytes., p. 111-162. In J. I. Gallin and A. S. Fauci (ed.), Advances in host defense mechanism, vol. 1. Raven Press, New York, N.Y.
37. Klein, J. B., V. Payne, T. M. Schepers, and K. R. McLeish. 1990. Bacterial lipopolysaccharide enhances polymorphonuclear leukocyte function independent of changes in intracellular calcium. Inflammation 14:599-611.

38. Kupsch, E.-M., B. Knepper, T. Kuroki, I. Heuer, and T. F. Meyer. 1993. Variable opacity (Opa) outer membrane proteins account for the cell tropism displayed by Neisseria gonorrhoeae for human leukocytes and epithelial cells. EMBO J. 12:641-650.

39. Leese, A. J., A. A. Campagnari, W. E. Bittner, and M. A. Apicella. 1990. Increased resolution of lipopolysaccharide and lipooligosaccharide utilizing tricine-sodium dodecyl sulfate-polyacrylamide gel electrophoresis. J. Immunol. Methods 126:109-117.

40. Lincoln, J. A, D. L. Lefkowitz, T, A. Cain, K. C. Castro, S. S. Mills, N. Lefkowitz, N. Moguilevsky, and A. Bollen. 1995. Exogenous myeloperoxidase enhances bacterial phagocytosis and intracellular killing by macrophages. Infect. Immun. 63:3042-3047.

41. Makino, S., J. P. van Putten, and T. F. Meyer. 1991. Phase variation of the opacity outer membrane protein controls invasion by Neisseria gonorrhoeae into human epithelial cells. EMBO J. 10:1307-1315.

42. McGee, Z. A., D. S. Stephens, L. H. Hoffmann, W. F. Schlech III, and R. G. Horn. 1983. Mechanism of mucosal invasion by pathogenic Neisseria. Rev. Infect. Dis. 5:S708-S714.

43. McNally, J. A., and A. L. Bell. 1996. Myeloperoxidase-based chemiluminescence of polymorphonuclear leukocytes and monocytes. J. Biolumin. Chemilumin. 11:99-106.

44. Meloni-Bruneri, L. H., A. Campa, D. S. Abdalla, V. L. Calich, H. L. Lenzi, and E. Burger. 1996. Neutrophil oxidative metabolism and killing of $P$. brasiliensis after air pouch infection of susceptible and resistant mice. J. Leukoc. Biol. 59:526-533.

45. Morel, F., J. Doussiere, and P. V. Vignais. 1991. The superoxide-generating oxidase of phagocytic cells. Eur. J. Biochem. 201:523-546.

46. Mosleh, I. M., L. A. Huber, P. Steinlein, C. Pasquali, D. Gunther, and T. F. Meyer. 1998. Neisseria gonorrhoeae porin modulates phagosome maturation. J. Biol. Chem. 273:35332-35338.

47. Müller, A., D. Günther, F. Dux, M. Naumann, T. F. Meyer, and T. Rudel. 1999. Neisserial porin (PorB) causes rapid calcium influx in target cells and induces apoptosis by the activation of cysteine proteases. EMBO J. 18:339-352.

48. Naids, F. L., and R. F. Rest. 1991. Stimulation of human neutrophil oxidative metabolism by nonopsonized Neisseria gonorrhoeae. Infect. Immun. 59:43834390.

49. Nikaido, H. 1992. Porins and specific channels of bacterial outer membranes. Mol. Microbiol. 6:435-442.

50. Oda, T., and H. Maeda. 1986. A new simple fluorometric assay for phagocytosis. J. Immunol. Methods 38:175-183.

51. Pabst, M. J. 1994. Priming of neutrophils, p. 196-227. In P. G. Hellewell and T. J. Williams (ed.), Immunopharmacology of neutrophils. Academic Press, London, England.

52. Reibmann, J., H. M. Korchak, L. B. Vosshall, K. A. Haines, A. M. Rich, and G. Weissmann. 1988. Changes in diacylglycerol labeling, cell shape, and protein phosphorylation distinguish "triggering" from "activation" of human neutrophils. J. Biol. Chem. 263:6322-6328.

53. Rider, L. G., and J. E. Niedel. 1987. Diacylglycerol accumulation and superoxide anion production in stimulated human neutrophils. J. Biol. Chem. 262: 5603-5608.

54. Sarafian, S. K., and J. S. Knap. 1989. Molecular epidemiology of gonorrhea. Clin. Microbiol. Rev. 2:S49-S55.

55. Tsai, C.-M., and C. E. Frasch. 1982. A sensitive silver stain for detecting lipopolysaccharide in polyacrylamide gels. Anal. Biochem. 119:115-119.

56. Tufano, M. A., F. Rossano, P. Catalanotti, G. Liguori, C. Capasso, A. Baroni, and P. Marinelli. 1994. Properties of Yersinia enterocolitica porins: interference with biological function of phagocytes, nitric oxide production and selective cytokine release. Res. Microbiol. 145:297-307.

57. Tufano, M. A., F. Rossano, P. Catalanotti, G. Liguori, C. Capasso, A. Baroni, and P. Marinelli. 1994. Immunobiological activities of Helicobacter pylori porins. Infect. Immun. 62:1392-1399.

58. Weel, J. E. L., and J. P. M. van Putten. 1991. Fate of the major outer membrane protein porin in early and late events of gonococcal infection of epithelial cells. Res. Microbiol. 142:985-993.

59. Weiss, S. J., and A. F. LoBuglio. 1982. Phagocyte-generated oxygen metabolites and cellular injury. Lab. Investig. 47:5-18.

60. Yee, J., and N. V. Christou. 1993. Neutrophil priming by lipopolysaccharide involves heterogeneity in calcium-mediated signal transduction. J. Immunol. 150:1988-1997.

61. Young, J. D. E., M. S. Blake, A. Mauro, and Z. A. Cohn. 1983. Properties of the major outer membrane protein from Neisseria gonorrhoeae incorporated into model lipid membranes. Proc. Natl. Acad. Sci. USA 80:3815-3835.

62. Zheng, H. Y., D. J. Hassett, K. Bean, and M. S. Cohen. 1992. Regulation of catalase in Neisseria gonorrhoeae. Effects of oxidant stress and exposure to human neutrophils. J. Clin. Investig. 90:1000-1006. 